УДК 536(075.8)

\title{
ПОЛЕ СОЛНЕЧНОЙ РАДИАЦИИ В РАСТИТЕЛЬНОМ ПОКРОВЕ
}

Драганов Б.Х., доктор технических наук

Национальный университет биоресурсов и природопользования Украины, ул. Г. Оборонь, 15, Киев, 03041, Украина

Наведено метод фотометричного опису листка і радіаційного режиму рослин у тіньовій і сонячній областях. Досліджено виробництво ентропії в процесі фотосинтезу, ієрархічність самоорганізації систем.
Приведен метод фотометрического описания листа и радиационного режима растений в теневой и солнечной областях. Исследованы производство энтропии в процессе фотосинтеза, иерархичность самоорганизации систем.
Shows a method for photometric description of leave and the radiation regime plants in shady and sunny areas. Studied entropy production in photosynthesis, hierarchical selforganizing systems.
Растительный покров представляет собой совокупность неоднородных и изменяющихся во времени частей, поэтому фотометрический анализ должен опираться на математико-статический метод. Отметим ряд работ, посвященных фотометрии.

Кинсрсон и Фрич [1] использовали метод статистической выборки для исследования характеристики хвойных лесов. В модели Саэки и Куройва [2] учитывается влияние части растений на функцию распределения листовой поверхности по высоте растения.

В методе Удагавы [3] вертикальное описание листовой поверхности в почве кукурузы определяется при помощи функции, имеющей вид кубической параболы. В работах $[4,5]$ выполнен анализ структуры распределения листьев по высоте стебля. На основе этих исследований получены соответствующие расчетные зависимости.

Радиационный режим растительного покрова (РП) формируется вследствие ряда факторов: интенсивности лучистой энергии солнечной радиации; воздействия лучистой энергии на биологические процессы в растении; расположения элементов растений, их геометрических и оптических свойств. При моделировании радиационного поля следует принять во внимание:

- архитектоника растительного покрова многообразна и изменяется в широких пределах. Элементы фитомассы имеют сложную фигуру, расположены своеобразно (не подчиняющие- ся определенному геометрическому порядку и, вместе с тем, структуру нельзя считать хаотичной) и это затрудняет их математическое описание;

- на верхнюю границу РП падает как прямая, так и диффузионная радиация Солнца;

- для зеленой растительности характерен большой коэффициент поглощения в области фитосинтетической активной радиации (ФАР) и малый в области близкой к инфракрасной радиации (БИКР). Вследствие этого в формировании режима ФАР в РП первостепенное значение имеет архитектоника растительного покрова - форма и размеры фитоэлементов, их размещение и ориентация, расположение растений в РП и т.д.

Методы математического моделирования режима радиационного покрова приведены в $[6,7]$. В этих работах элементы растительности рассматриваются как поглощающие и рассеивающие частицы с заданными геометрическими и оптическими свойствами. Используется модель анизотропной среды, которая в достаточной степени точно отражает физическую картину РП.

При анализе радиационного поля в РП следует принимать во внимание все составляющие радиационного потока: прямого, рассеянного и отраженного.

Плотность потока прямой солнечной радиации в растительном покрове может изменяться в значительных пределах. В солнечных бликах она близка к полному значению $S_{0}$ над РП, а в области тени может быть принята равной нулю. Если 
в первом приближении пренебречь полутенями, то можно рассматривать Солнце как точечный источник и анализируемый процесс может быть записан при помощи дельта-функции Дирака. В статистическом рассмотрении прямая солнечная радиация записывается в виде случайной функции $X_{s}(x)$, имеющей только два значения

$X_{S}(x)=\left\{\begin{array}{l}0, \text { в теневой области; } \\ S_{0}\left(r_{S}\right), \text { в солнечных бликах. }\end{array}\right.$

Интенсивность рассеянной радиации зависит от высоты Солнца и количества рассеивающих элементов в атмосфере. Важной характеристикой рассеянной радиации, кроме спектрального состава, является ее угловое распределение, определяемое формой индикатрисы рассеяния и оптической толщиной атмосферы.

Среди оптических характеристик РП одной из наиболее существенных является альбедо [8]. Альбедо - величина, характеризующая способность поверхности какого-либо тела отражать (рассеивать) падающее на него излучение. Наряду с интегральным альбедо для всего потока излучения различают также альбедо монохроматическое и альбедо в различных областях спектра (ИК, видимое, УФ).

Небольшие изменения оптических свойств фитоэлементов в области БИКР могут вызвать заметные изменения альбедо РП в этой области спектра. В области ФАР альбедо густого РП небольшое (в пределах 0,03...0,07), в области ВИКР альбедо равно 0,4 ..0,5 и в области КВР $0,23 \ldots 0,27$.

В области ФАР зависимость альбедо от ориентации листьев несущественна и ею можно пренебречь. В области БИКР и КНР влияние ориентации листьев существенно при больших и малых высотах Солнца альбедо практически не зависит от ориентации листьев.

На основе разработанной математической модели расчетом получены графики, выражающие зависимости показателей фотосинтеза от определяющих параметров в случае строгой согласованности спектра фотоактивности со спектром воздействующего света. Для квазимонохроматического излучения этому требованию отвечают системы с узкополосным поглощением. При математическом моделировании радиа- ционного поля в растительном покрове следует принимать во внимание следующие факторы:

- закономерность размещения растений на подстилающей поверхности и неоднородность размещения фитоэлементов в пределах обьема растения;

- учет полутени, во многом обусловливающей неоднородность радиационного поля в растении;

- изменчивость во времени радиационного поля внутри РП.

Заслуживают внимания исследования, посвященные термодинамическому анализу эндоэргических процессов, которые позволили установить условия их эффективности по величине производства энтропии [10]. В настоящее время наиболее обоснованная концепция анализа биологических процессов основывается на подходе Пригожина [11].

Результаты исследований дают основание утверждать, что производство энтропии изменяется линейно от воздействующего параметра. В данном случае имеется ввиду поглощенная мощность излучения, а более точно, спектральная плотность поглощаемой мощности:

$S_{e}+S_{i}=W_{e} / T$,

где $S_{i}$ - производство энтропии эндоэнергетических процессов, происходящих как в живых организмах, так и в технических устройствах; $S$ - производство энтропии окружающей среды; $W_{e}-$ мощность поглощенного излучения; $T-$ температура.

Параметр $S_{i} / S_{e}$ может служить характеристикой с целью совершенства процесса фотосинтеза.

Несомненный интерес представляет концепция, что обязательной особенностью синтеза генетической информации является иерархичность. Новый $k$-й уровень синтеза информации возникает на основе учета свойств элементов предыдущего уровня иерархии $[10,12]$.

Иерархический ряд для энтропий как мера информации записывается в виде:

$S_{n}=S_{0}+S_{1 \mid 0}+S_{2 \mid 0,1}+\ldots,+S_{k \mid 0,1,2, \ldots,(\mathrm{k}-1)}$,

где члены $S_{k \mid 0,1,2, \ldots,(\mathrm{k}-1)}$ определяются на основе условных вероятностей, учитывающих синтез информации, относящейся к предыдущим ступеням иерархии. 
Развитие в природе происходит на основе иерархии цепочки: случайность-условиязапоминание. Синонимом запоминания в природе служит устойчивость ее объектов и процессов. В результате происходит непрерывное развитие, в процессе которого энтропия растет, но иерархическими ступенями [13].

Случайности, приводящие к детерминизму, и есть главная причина реальности множественности жизни. Иерархичность самоорганизации систем означает, что сам хаос, само существование энтропии есть основа детерминизации запоминаемого объекта, т.е. синтезированной в нем информации .

\section{Заключение}

Эффективный метод анализа поля радиации солнечной энергии в покрове растений основывается на концепции термодинамики биологических процессов. Иерархичность самоорганизации систем означает, что значение производства энтропии служит характеристикой необратимости в живых средах. Иерархичность самоорганизации служит основой самоорганизации систем.

\section{ЛИТЕРАТУРА}

1. Kinerson R., Fritshen L.J. Modeling a coniferous forest canopy.// Agic. Meteorol, vol. 8, No. 6, 1971, P. 439-445.

2. Saeki T., Kuroiwa S. On the establishment of the vertical distribution of photosynthetic system in plant community//Botanical Magazine (Tokyo), 1959, vol. 72, № 848. P. 27-35.

3. Udagawa T. et. al. Canopy structure of corn plant // Photosynthesis and Utilization of Solar Energy. Level III. 1968, P. 20-24.
4. Horie T. Vertical distribution of photosynthesis and Utilization of Solar Energy. Level III, 1970, P. 9-15.

5. Росс Ю., Росс В. Вертикальное распределение листовой поверхности в посевах. - В кн.: «Фотосинтетическая продуктивность растительного покрова». - Тартару, 1969. - С. 44-59.

6. Росс Ю. Математическое моделирование поля фотосинтетически активной радиации (ФАР) в растительном покрове. - В кн.: «Актинометрия и оптика атмосферы». М.: Наука, 1964. - C. 251-256.

7. Cowan I.R. The interception and absorption of radiation in plant stands // J. of Appl. Ecology, 1968. - Vol. 5. - P. 367-379.

8. Шифрин К.С. К теории альбедо // Труды ГГО, 1953. - Вып. 39. - № 101. - С. 244-257.

9. Warren Wilson J. Influence of spatial arrangement of foliage area on light interception and pasture growth. - In/: Proceedings of the 8-th International Grassland Congress, 1961. - P. 275279.

10. Draganov B.H. Entropy and dynamics of hierarchical systems in the analysis of the evolution of living structures // Termotechnica. - 2007. - Anul XI. №1/2 - P. 20-22.

11. Пригожин И. Современная термодинамика от тепловых двигателей до диссипативных структур/ И. Пригожин, Д. Кандепуди // М.: Мир, $2002,-461$ c.

12. Долинский А.А. Энтропия эволюции живых существ // А.А. Долинский, Б.Х. Драганов // Промышленная теплотехника. - 2005. - Т. 27 - № $6-$ C. $7-9$.

13. Prigogine I., 1969. Structure, dissipation and life. - In.: Theoretical Physics and Biology. NorthHolland Publ. Co., P. 23-52.

Получено 07.05.2015 Received 07.05.2015 